\title{
Reshaping of the retail environment due to internet as a global competitor
}

\author{
Lubica Gajanova ${ }^{1, *}$, and Margareta Nadanyiova ${ }^{1}$ \\ ${ }^{1}$ University of Zilina, The Faculty of Operation and Economics of Transport and Communications, \\ Department of Economics, Univerzitna 1, 01026 Zilina, Slovakia
}

\begin{abstract}
According to statistics, the number of Slovaks who shop over the Internet is increasing year by year. Compared to the surrounding countries, Slovaks are clearly the leaders in online shopping. Increasing popularity of customers in online shopping leads to a significant decline in number of retail stores. This is a consequence of global technological change. However, businesses and especially retailers themselves can benefit from technological advances in this case as well. All you have to do is choose the right marketing tool. Such tools are undoubtedly the tools of proximity marketing that are used as a communication channel in retail stores. In this paper, we focus on proximity marketing tools that provide a means of creating a personal relationship between a customer and a vendor at the time of physical purchase by a customer in a store. Its aim is to support and increase sales in retail stores, increase consumer satisfaction and build a positive brand image. The aim of the paper is to analyse the possibility of using proximity marketing for Slovak consumers as one of the possibilities of reshaping of the retail environment. This analysis will be realized from demographic and also from psychographic point of view.
\end{abstract}

\section{Introduction}

As technology evolves, supply and demand for online sales and purchases are increasing. Of course, this kind of shopping has a valid meaning. But what can retailers who only offer their merchandise in a retail store to do? How to deal with the phenomenon of the present time when a customer orders goods from an online store via a few clicks [1]? Paradoxically, the answer can be found in the field of mobile marketing. Despite the fact that smartphones and other mobile devices caused a decrease in retail sales and thus a large distance of customers from the physical point of sale, mobile marketing is currently offering a solution to such a problem [2]. There are two areas of mobile marketing whose concept is based on the location and proximity of the customer to the physical point of sale, that is, to the retail store. This is local based marketing and proximity marketing [3].

The aim of the paper is to analyse the possibility of using proximity marketing for Slovak consumers as one of the possibilities of reshaping the retail environment. This analysis shows the evident presence of proximity marketing on the Slovak market, but also shortcomings in the area of proximity marketing on the domestic market, primarily on the

*Corresponding author: lubica.gajanova@fpedas.uniza.sk 
supply side. For this reason, a questionnaire survey of the perception of proximity marketing activities by Slovak consumers was carried out, in which we also dealt with the psychographic point of view of the issue.

\section{Literature review}

Already in 2008, traders were increasingly initiating a placement-targeted ad. It was likely that the privacy of consumers who received advertising messages in specific locations played an important role in determining how consumers responded to this type of marketing communication. At that time, physical surroundings and places formed consumer actions and responses and represented an important element of the context. A place can influence people's behaviour and his perception of various information as well $[4,5]$. This was one of the reasons, why mobile marketing began to focus more closely on proximity issues. Because it has happened many times, that a customer who was not interested in buying from a particular merchant received from him ad on his device. On the one hand, the customer could perceive such advertising as annoying and, on the other hand, the trader made unnecessary efforts to reach the customer. It was more efficient for the trader to reach the customer who was in close proximity to his store or directly in the shop and concentrate on communicating with him [6].

In 2008, the concept of proximity marketing was defined for the first time. This concept was based on the need to develop location-based marketing. While location-based marketing communication ensures the quantity of communication with potential customers, the implementation of proximity marketing communication focuses on the quality of communication with potential customers [7]. For the best understanding of the concept of proximity marketing it is necessary to define the term proximity. Proximity means zooming in space, time, or relationship. The basic characteristics of this marketing direction stem from the concept of proximity. Various authors have contributed their views and studies of proximity marketing to its formation up to its present form. As with mobile marketing, proximity marketing has evolved under the influence of technology developments [8].

Proximity marketing thus became the missing link needed to close the last gap between customer and merchant. The idea of proximity, physical placement of the product in relation to the consumer has highlighted a new dimension that has not been used in the past because of technology constraints. Proximity marketing uses mobile technology to send marketing messages to mobile device of users who are in close proximity to the store. Through Wi-Fi or Bluetooth signals, merchants can send content that is automatically displayed on consumer mobile devices. This leads to the selection of the addressed customers and thus to the targeting of a specific group of customers, who most likely buy directly from the given merchant $[8,9,10,11]$. According to a research study conducted by a team of marketing experts from Laval University, proximity marketing is a distribution channel for site-specific advertising. The communication that the merchant initiates for the dissemination is wireless and based on the geographic location of the customer against the store. The customer's mobile device that supports Wi-Fi, Bluetooth, or Near Field Communication is a tool of communication transmitting. This means that merchants must send their advertising content to target geographic locations where potential customers have been identified [12].

The most characteristic feature of proximity marketing is unequivocally the consideration of mobility and geolocation of consumers in real time through wireless and interactive technologies. This fact was pointed out by the authors already in 2007 [13]. However, some characteristics have changed or added to the original initial definitions. These changes have accompanied the development of proximity marketing to the present. 
According to one of the latest generally applicable definitions of proximity marketing in the world, proximity marketing can be seen as a form of local advertising where timely, relevant and personal communication takes place between the consumer and the trader. Accurate customer placement and involvement in specific and contextual communication is important. This communication cannot be implemented through location-based marketing. Mobile device location detection through proximity marketing tools can be achieved only in a few meters. As a rule, this is the area of a particular store or a department in the store. Because of the ability to create communications over such a short distance, it is possible to initiate targeted and personalized communications that provide relevant information to the customer $[14,15,16]$.

\section{Analysis of the current status of proximity marketing in the Slovak republic}

According to GFK's analytical and research agency, approximately $67 \%$ of Slovaks own a smartphone. This is also confirmed by a survey conducted by Market Locator. The analysis was performed on a sample of 2.9 million inhabitants of the Slovak Republic. Data from three mobile operators in Slovakia (Telekom, Orange and O2) were used for this purpose. Surveys show that more than $67 \%$ of users own smartphones, only about $32 \%$ of mobile phone users use a mobile phone with an older type of operating system that does not allow the use of additional applications. It is the smartphone that is the most frequently used mobile device that enables the implementation of proximity marketing to customers. All smartphones meet the requirements that require the use of proximity marketing tools. In addition, many non-smart phones meet these requirements. Of course, the content that is displayed through such a mobile phone may not be in the same quality or scope as it is for smartphones, tablets and other mobile devices with the latest operating systems [17].

From the results above we can say that addressing consumers of the Slovak Republic through proximity marketing is feasible. More than half of the Slovak population owns a smartphone, the most widely used device for the implementation of proximity marketing, which represents a considerable potential for success for businesses. But the reality is different.

The first tools of proximity marketing were Bluetooth beacons. In Slovakia, this technology appeared for the first time in 2008. That is, at the birth of proximity marketing in the world. It was a one-time campaign of Glamor Slovakia, which is the distributor of ESCADA in Slovakia. It was an unconventional and innovative form aimed at young women who were mobile users. The main goal of this campaign was to attract customers intently and attract interest in getting a sample or buying a new perfume. The decision to promote the introduction of women's fragrance by Bluetooth was supported by a detailed analysis of the behaviour of the target group by ESCADA. The fact that proximity marketing has been applied in Slovakia at the very beginning can be considered as a success that predicts the potential of using proximity marketing in the Slovak market. Whether the proximity marketing tools were applied in the business environment, or to what extent these tools were used in the period after 2008, to some extent influences the current state of proximity marketing in Slovakia.

To analyse the current situation, we decided to accost several marketing and digital agencies that focus on proximity marketing or at least some of the tools of proximity marketing. In addition, we got onto several companies that provide technologies for such marketing solutions.

The most common tool used in Slovakia are QR codes. QR codes were one of the first proximity marketing tools to be used in Slovakia in 2011. Nowadays, they can be found almost everywhere. But the truth is that few people actually use them. In the analysis we 
tried to find out the potential of QR codes from interviews with marketing specialists. Their opinions almost coincided. Most of the addressed marketers do not see much importance in QR codes, mainly because of the many limitations that this technology has. Customers want everything immediately and without much effort. Despite the many shortcomings with which QR codes limit the effective functioning of the proximity marketing campaign, this technology is still being applied. This stems from the fact that it is a well-established thing, which constitutes a kind of standard of a complex marketing campaign, and the customers do not often care that the effectiveness of this tool is scarce.

According to the representatives of companies, the demand for proximity marketing tools is scarce. Proximity marketing tools are considered as only complementary or supportive. In addition to QR codes, Wi-Fi is also used as one of the proximity marketing tools. The most common way to use this technology is to characteristic name the Wi-Fi network. An enterprise can change its Wi-Fi network name to the current campaign or action in progress to attract bystanders. Interest in this solution is on the increase but this kind of proximity marketing is not always realized through a marketing agency or specifically as a kind of proximity marketing. Businesses that want to differentiate themselves from the competition are actively pursuing the latest trends in the marketing world, as well as their competitors, and if they are able to implement some of the marketing solutions themselves, they will. Many entrepreneurs may not even know that they use the proximity marketing tool.

However, there are exceptions. Companies that are trying to bring new trends in proximity marketing to our market. There is also demand, that is, businesses that want to be innovative and reach their customers differently than competitors. One decade has passed since 2008 and the first companies are starting to appear on the Slovak market using Bluetooth beacons, namely iBeacons. Orange Slovakia, in cooperation with a marketing agency, wanted to enhance the teambuilding of its employees with something new, and created a connection of the marketing campaign with an interactive game. The game is implemented through a mobile application that processes the signal transmitted from the Bluetooth beacons. The lighthouses were installed in Banská Štiavnica for one month. Upon receiving the signal to the smartphone from the beacon, the player's position is identified and the game progresses. The main aim of Orange Slovakia was to delight its employees, deepen teamwork and, last but not least, to promote the Huawei mobile device as a high-tech device, through which this teambuilding competition in Banská Štiavnica was realized.

Another significant use of iBeacons in Slovakia was created by Songoroo. This is a completely different dimension of proximity campaign in practice, but it fulfils the essence of marketing proximity. Songoroo is an interactive music system for businesses. Customers entering the shop are notified by leaflets or posters that Songoroo can be downloaded. It is a music application through which a customer can influence the list of songs in a given space or part of it with their music preferences. You need to have Bluetooth turned on your mobile device, and as soon as the signal from the Bluetooth beacon is picked up, the playlist can be influenced by the app. Of course, not just a special atmosphere is the main benefit of this campaign. The companies involved in this unique concept acquire customer preference data to further capture the atmosphere of the business and adapt it to different parts of the day, depending on the composition of its customers.

This analysis shows the evident presence of proximity marketing in the Slovak market. However, it is clear that the level of use of proximity marketing tools is not comparable to foreign countries such as the US, the UK and others. The views of marketing agency owners, marketing specialists and proximity marketing users themselves vary. In one case, however, all the companies addressed agree that there is a high lack of interest in developing a campaign using proximity marketing tools. According to the owners of the 
addressed companies and marketing specialists, some entrepreneurs have no idea that proximity marketing exists or its benefits. Many businesses are only set up to monitor competition, their market presence and do not focus on innovative tools. This is also one of the reason why marketing agencies do not invest in expanding their portfolios. This is the cause why the tools of proximity marketing do not work in the Slovak market as much as abroad. Entrepreneurs do not create demand, so marketing and digital agencies are not motivated to offer these services.

\section{Methodology}

We demonstrated the presence of proximity marketing tools on the Slovak market by analysing the current state of proximity marketing. Based on the analysis, we have identified significant shortcomings in the area of proximity marketing in the domestic market on the supply side. We therefore consider it necessary to conduct a survey of consumer perception of proximity marketing activities. We created a questionnaire survey to carry out a survey of consumer perception of proximity marketing activities in the Slovak Republic. To ensure the fulfilment of the objective of marketing research, we have set the main research assumption, which is as follows: The potential of using marketing proximity in the business practice of the Slovak Republic exists [18].

On the basis of the main research assumption, we have established hypotheses, by which we obtain the basis for proposals and recommendations for the practice of companies in the Slovak Republic. Based on the set problem and the goal of the marketing research, we decided to carry out the marketing research on a sample of consumers of the Slovak Republic. The size of the representative sample was determined by according to Moravčíková et al. [19]. In order to conduct a marketing survey of the perception of proximity marketing activities by consumers in the Slovak Republic, it is necessary to provide a sample of at least 385 respondents. In order to carry out a qualitative survey, a questionnaire was chosen as a tool for data acquisition. The questionnaire ensured finding the perception of proximity marketing activities by consumers in the Slovak Republic. The survey was conducted in April 2019. The 568 respondents participated in the questionnaire survey.

\section{Results}

We asked consumers for their general attitude towards mobile communications between traders and customers in the store. The results show that only $15 \%$ of consumers do not have a positive attitude towards this form of communication. $16 \%$ of consumers said they appreciated this kind of communication. $30 \%$ of consumers expressed a neutral attitude and $39 \%$ of consumers did not express their attitude because they did not meet this type of communication.

In the survey we were interested in what mobile phone is owned by as well. Slovak consumers. It is the smartphone that represents the most frequently used proximity marketing tool in the retail business. Subsequently, we used the data for statistical testing of the first hypothesis: $70 \%$ of consumers in the Slovak Republic prefer using smartphones over non-smart mobile phones. We set an alternative hypothesis. It is clear from the formulation of the alternative hypothesis that this is a right-tailed test.

After checking of the condition $(568 * 0,7 * 0,3>5 ; 119,28>5)$ we calculate the value of the variable $\mathrm{T}$, according to the relation:

$$
T=\frac{0,850-0,7}{\sqrt{\frac{0,7 \times[1-0,7)}{568}}}=7,819
$$


Decision: We reject $\mathrm{H} 0$ at significance level $\alpha=0.05$. The decision shows that more than $70 \%$ of consumers in the Slovak Republic prefer to use smartphones over non-smart mobile phones.

The sample of consumers of the Slovak Republic was divided into 4 generations based on age (Betz, 2019). Generation $\mathrm{Z}$ is represented by $18 \%$ of respondents, Generation $\mathrm{Y}$ by $46 \%$ of consumers, Generation X by $18 \%$ of consumers. The last group the Baby Boomers generation accounts for $18 \%$ of consumers.

We used the data to statistically testing of the second hypothesis: There is no statistically significant relationship between consumer age and smartphone usage.

Table 1. Test Statistics - Hypothesis 2.

\begin{tabular}{|l|r|r|r|}
\hline & \multicolumn{1}{|c|}{ Value } & df & Asymptotic Significance (2-sided) \\
\hline Pearson Chi-Square & $194,970^{\mathrm{a}}$ & 3 &, 000 \\
\hline Likelihood Ratio & 160,835 & 3 & 000 \\
\hline N of Valid Cases & 568 & & \\
\hline a. 0 cells (0,0\%) have expected count less than 5. The minimum expected count is 15,26. \\
\hline
\end{tabular}

Based on the test result, it is clear that the value of the variable $p$ is lower than the determined significance level $\alpha(0.05)$. It means we reject $\mathrm{H} 0$. So we can say that there is a statistically significant relationship between the age of consumers and the use of a smartphone.

Consumers' preferences to shop online or in the store, as well as the factors that were decisive for the purchase, were another aspect we examined. The most important factors that consumers have decided to buy online are: saving money (this is clearly the top priority for 55 percent), easy shopping ( 28 percent), better choice of goods (26 percent) and faster purchases (25 percent). As the fifth most important factor, one in five shoppers (21 percent) said they would get better information online. As well as one in five customers said they were already shopping online. However, four of the above factors affecting the decision to shop online also appear among the five reasons that lead to the decision to shop in retail. The main factor that leads customers to buy in a traditional shop rather than over the Internet is that they can view and feel the products before purchasing (51 percent). Other decisive reasons are more interesting. A third of shoppers said they opted for a particular shop purchase rather than online because shopping in the shop is easier - compared to 28 percent of those who find it easier to shop online. Another important reason for shopping in a store is the possibility of a simpler return of goods (29 percent), followed by the fact that the consumer normally purchases there ( 28 percent). The fifth factor that most influences the decision to make a purchase in a store is equally divided between better information and saving money (22 percent).

With respect to the psychographic point of view of the problem we have set another hypothesis: There is no statistically significant dependence between the age (generation) of consumers and the preference of online / offline purchasing.

Table 2. Test Statistics - Hypothesis 3.

\begin{tabular}{|l|r|r|r|}
\hline & \multicolumn{1}{|c|}{ Value } & df & Asymptotic Significance (2-sided) \\
\hline Pearson Chi-Square & $6,914^{\mathrm{a}}$ & 3 & 0,075 \\
\hline Likelihood Ratio & 6,930 & 3 & 0,074 \\
\hline N of Valid Cases & 568 & & \\
\hline
\end{tabular}


Based on the test result, it is clear that the value of the variable $p$ is greater than the determined significance level $\alpha(0.05)$. This means we do not reject H0. So we can say that there is no statistically significant dependence by favouring online / offline purchasing.

Building on the previous hypothesis, we have investigated whether consumers are willing to favour a physical store purchase rather than an e-shop purchase if they get a reward or a discount to purchase from a physical store. 33\% of consumers said yes, and up to $53 \%$ of consumers said probably yes. Despite the advantage, only $3 \%$ of consumers would not prefer to buy in-store rather than shopping through an e-shop, and $11 \%$ of consumers probably would not prefer such a preferential purchase.

\section{Discussions}

The fact that the proximity marketing activities as a form of communication between the business and the consumer needs to be actively developed in Slovakia is also supported by the evaluation of the survey, through which we found out, among other things, the attitude to the form of communication between the consumer and businesses via mobile phone. Based on the results, it can be said that the potential of using proximity tools as a form of communication between the seller and the customer during the in-store purchase exists. It should be borne in mind that a large number of consumers do not know the benefits and the way in which the business communicates with the consumer at the point of sale through the consumer's mobile phone or other consumer's mobile device. We recommend starting with the use of proximity marketing technologies gradually and also carefully selecting the circle of consumers to whom such communication will be addressed. The results of the questionnaire survey as well as the verification of the statistical hypothesis show that there is a statistically significant relationship between the age of consumers and the use of smartphones. Because the tool through which proximity marketing is realized is mostly a customer's smartphone, businesses that focus on Baby Boomers and Generation X customer segments need to review the use of these tools in their marketing strategy, or assess the proximity marketing activities set up in their store with respect to the selected customer segment. Shops are putting increasing pressure on retail stores. Several researches suggest that the future is in the online store. However, the factors that motivate consumers to make physical purchases versus online purchases do not differ as much as one might expect. A generation that lives by technology is not much different from older people in consumer behaviour and still prefers personal contact and an experience that the online world is not yet able to replace, the survey showed [20,21]. When it comes to shopping, both the millennials and the older generation find it most important to feel the product in a physical store and take it with you right away [22]. In addition, the survey shows up to $86 \%$ of consumers have a positive attitude towards rewarded or discounted purchases in a physical store. Thus, by properly adjusting proximity marketing activities, it is possible to increase the amount of physical purchases made in a physical store.

\section{Conclusion}

At the end of the evaluation of the survey of consumer perception of proximity marketing activities, it is necessary to give an opinion on the main research assumption, which is: "The potential of using proximity marketing in the business practice of the Slovak Republic exists." With regard to the evaluation of all questions of the questionnaire survey and with regard to the results of statistical verification of established hypotheses, we can say that there is a presumption for the practice of companies in the conditions of the Slovak Republic to successfully implement and utilize proximity marketing activities. 


\section{References}

1. W. Ozuem, G. Bowen,. Basics of Mobile Marketing Strategy IN: Competitive Social Media Marketing Strategie (IGI Publications, Hershey, 2016)

2. A. Landmark, D. Andreas, B. Sjobakk, Tracking customer behaviour in fashion retail using RFID. International journal of retail \& distribution 45, 7-8, 844-858 (2017)

3. (n.d.). Retrieved from https://study.com/academy/lesson/what-is-proximitymarketing-definition-examples.html.

4. R. R. Dholakia, N. Dholakia, Mobility and markets: Emerging outlines of $\mathrm{m}$ commerce. Journal of Business Research 57, 12, 1391-1396 (2004)

5. K. Willems, M. Brengman, S. van de Sanden, In-store proximity marketing: experimenting with digital point-of-sales communication. International journal of retail \& distribution 45, 7-8, 910-927 (2017)

6. J. M. Cheng, C. Blankson, E. S. Wang, L. S.Chen, Consumer attitudes and interactive digital advertising. International Journal of Advertising 28, 3, 501-525 (2009)

7. J. Arnold, I. Lurie, M. Dickinson, E. Marsten., M. Becker, Web marketing all-in-one for dummies. (John Wiley \& Sons, NJ, 2012)

8. G. Petro (2014, October 8). How Proximity Marketing Is Driving Retail Sales. Retrieved from https://www.forbes.com/sites/gregpetro/2014/10/08/how-proximitymarketing-is-driving-retail-sales/\#793-b6bea3ed4

9. B. Page, Z. Anesbury, S. Moshakis, Measuring Audience Reach Of Outdoor Advertisements Using Bluetooth Technology To Validate Measurement. Journal of advertising research 58, 4, 456-463 (2018)

10. B. K. Clark, E. A. Winkler, C. L. Brakenridge, Using Bluetooth proximity sensing to determine where office workers spend time at work. Plos one 13, 3, e0193971 (2018)

11. S. Griffiths, M. S. Wong, C. Y. T.. Kwok, Exploring Bluetooth Beacon Use Cases in Teaching and Learning: Increasing the Sustainability of Physical Learning Spaces. Sustainability 11, 15, 4005 (2019)

12. N. Levesque, H. Boeck, F. Durif, A. Bilolo, The Impact of Proximity Marketing on Consumer Reaction and Firm Performance: A Conceptual and Integrative Model. In Twenty-first Americas Conference on Information Systems (Fajardo, Puerto Rico, 18, 2015)

13. J. Curtin, R. J. Kauffman, F. J. Riggins, Making the 'MOST' out of RFID technology: A research agenda for the study of the adoption, usage and impact of RFID. Information Technology and Management 8, 2, 87-110 (2007)

14. D. Salto Proximity Marketing: The New World of Mobile Marketing. (Amazon Digital Services LLC, 2018)

15. J. M. Cress, T. Beckamn, T. Proximity Marketing Guide for the Real Estate Industry. (Amazon Digital Services LLC, 2018)

16. W. Sroka, M. Lorinczy, The Perception of Ethics in Business: Analysis of Research Results. Procedia Economics and Finance 34, 156-163 (2015)

17. M Menšík, (2018, May 23). Smartfóny už využívajú dve tretiny Slovákov, dominuje Android. Retrieved from https://www.mojandroid.sk/smartfony-vyuzivaju-dvetretiny-slovakov/.

18. L. Gajanova, M. Nadanyiova, J. Kliestikova, J. Olah, The Potential of Using Bluetooth-based System as a Part of Proximity Marketing in the Slovak Republic. Marketing and Management of Innovations 2, 239-252, (2019)

19. D. Moravcikova, A. Krizanova, J. Kliestikova, M. Rypakova, Green Marketing as the Source of the Competitive Advantage of the Business. Sustainability 9, 12, 2218 (2017) 
20. J. Majerova, Analysis of Specifics in Buying Behavior of Slovak Customers in Internet Environment. In 2nd International Conference on Social Sciences Research (Hong Kong, China, 172-178, 2014)

21. J. Kliestikova, K. Janoskova, Branding with understanding: how national profile of consumer influences brand value perception. Marketing and management of innovations, 3, 149-157 (2017)

22. A. Krizanova, J. Majerova, The proposal of activities of pricing policy in the process of building and managing brand value in Slovak Republic. In International Conference on Information, Business and Education Technology (ICIBET) (Beijing, China, 416-419, 2013) 